\title{
Conciliação e tensões entre trabalho e família para mulheres titulares do Programa Bolsa Família
}

Conciliation and tensions between work and family for women holders of Bolsa Família

A tríade Estado, mercado e família forma a base a partir da qual devemos pensar a reprodução social da vida e da proteção aos indivíduos na sociedade contemporânea, o que não significa supor que haja qualquer relação harmônica entre essas três esferas. Das problemáticas relativas às diferentes formas de articulação, ou de tensão, entre essas três esferas, surgiram diversos esquemas analíticos que geralmente enfocam duas dessas dimensões - Estado e mercado. Este é o caso, por exemplo, das formulações de Esping-Andersen (1991), que priorizaram a interação Estado e mercado como critério para a distinção entre as três economias do Welfare State. Nessa proposta, a desmercadorização, isto é, a oferta de bens e serviços pelo Estado, em substituição ao mercado, é um princípio fundamental para a análise da proteção social. Ainda operando com a díade Estado e mercado, outros trabalhos de referência foram desenvolvidos para tratar de temas como a questão social, a justiça e o desenvolvimento econômico e humano, a exemplo de Habermas (1987), Oliveira (1988), Castel (1998) e Rawls (2002), entre outros.

Os estudos feministas, por seu turno, ao interpelar, por exemplo, a situação

É professora do Departamento de Ciências Sociais da Universidade Estadual de Londrina. E-mail: <silvanamariano@yahoo.com.br>.

* É professor do Instituto de Ciências Sociais da Universidade Federal de Uberlândia. E-mail: <marcfs@ uol.com.br>.

*** Agradecemos ao CNPq pelo financiamento que possibilitou a realização da pesquisa “Discriminação interseccional: estudos sobre situações de pobreza e empoderamento feminino entre mulheres titulares do Programa Bolsa Família no Paraná e no Ceará - 2014", que originou este artigo. Agradecemos à Maria Andrea Luz da Silva e Maria Helena de Paula Frota, ambas da Universidade Estadual do Ceará, pelo planejamento, realização e registro do trabalho de campo feito em Fortaleza. 
de cidadania das mulheres, sua forma de inserção no mercado de trabalho, seu atendimento pelas políticas sociais, sua participação no desenvolvimento humano e as implicações das relações familiares para as hierarquias de gênero, contribuem para o esforço de produzir análises que buscam equacionar as interações entre essas três esferas - Estado, mercado e família (Moore, 1996; Fonseca, 2001; Pereira-Pereira, 2004; González de la Rocha, 2004).

De que modo e com que lógica as mulheres são atendidas pelas políticas sociais e inseridas em programas de desenvolvimento? Quais são os efeitos dessa inserção para a produção, reprodução ou alteração das relações entre homens e mulheres, fundadas nos padrões de gênero? Questões como essas mobilizam parte da agenda de pesquisa feminista orientada para o campo das investigações sobre gênero e desenvolvimento. Munidos de motivações como essas, neste trabalho, examinamos em quais condições essas mulheres lidam com a conciliação entre trabalho remunerado e cuidado.

As análises são desenvolvidas com base em estudos de caso realizados nos municípios de Curitiba (PR) e Fortaleza (CE). A amostragem completa da pesquisa é constituída por 190 entrevistas, sendo 95 em cada cidade, e o instrumento de coleta de dados foi um questionário composto por perguntas fechadas e abertas. As perguntas abertas foram codificadas com base na análise de conteúdo ${ }^{1}$ e o conjunto de informações foi registrado em programa de análise estatística para a formação de banco de dados. As entrevistas foram realizadas em sedes dos Centros de Referência de Assistência Social (CRAS). Para este trabalho em particular, consideramos uma subamostra de 89 entrevistadas, que compreende especificamente as mulheres que exercem trabalho remunerado.

As duas cidades são capitais de seus respectivos estados, sendo Curitiba localizada no Sul do Brasil e Fortaleza na região Nordeste. São grandes as disparidades sociais quando se comparam os contextos dessas duas regiões, o que se pode ilustrar pelos indicadores das duas capitais. Entre os indicadores, destacamos:

Fortaleza figura-se como a quinta cidade mais desigual no mundo.

Fortaleza [é] a capital mais densamente povoada do Brasil, e a quarta capital em número de aglomerados subnormais [...] com uma população de 369.370 habitantes ( $16 \%$ da população total) vivendo em condições mínimas de vida, de acordo com dados do Censo Demográfico 2010 do IBGE (Ipece, 2012, p. 3). 
Enquanto o Brasil tem 5,4\% dos domicílios com renda superior a 5 SM, Curitiba tem $25,4 \%$ dos domicílios com essa renda. Enquanto o Brasil tem 7\% dos seus domicílios com renda entre 2 e 3 SM, Curitiba tem 13,5\%. Enquanto o Brasil tem 10,4\% dos domicílios com renda inferior a 1/4 do SM, em Curitiba esse percentual chega a $1,1 \%$. Curitiba é a capital com o menor percentual de domicílios com renda inferior a 1/2 Salário Mínimo - 5,6\%, junto com Florianópolis. No Brasil esse percentual é de 27,6\% dos domicílios (IPPUC, 2012, p. 5-6).

A realização da pesquisa em dois contextos sociais tão diversos teve como objetivo abarcar os possíveis efeitos do Programa Bolsa Família (PBF) a partir de diferentes cenários de vulnerabilidade social. Para o ano de 2010, o Índice de Desenvolvimento Humano Municipal (IDHM) de Curitiba foi de 0,823 , ocupando o $10^{\circ}$ lugar no ranking nacional. No mesmo ano, Fortaleza ocupava a $467^{\text {a }}$ posição, com IDHM de $0,754^{2}$.

O Programa Bolsa Família foi instituído em 2003 como um programa de transferência de renda condicionada ${ }^{3}$, com o objetivo de favorecer as famílias em situação de pobreza, tendo em vista a promoção do "alívio imediato da pobreza”. Conforme o relatório Primeiros resultados da análise da linha de base da pesquisa de avaliação de impacto do Programa Bolsa Família:
A ruptura do ciclo intergeracional da pobreza é esperada por meio das condiciona- lidades que reforçam o exercício de direitos sociais nas áreas de saúde e educação [...]. Os critérios de elegibilidade do Bolsa Família partem da definição de situação das famílias na pobreza, com ocorrência de crianças até 15 anos de idade, gestantes e nutrizes, e famílias em extrema pobreza, com ou sem ocorrência de crianças, gestantes e nutrizes (MDS, 2007, p. 2).

O ranking do IDHM dos municípios de 2010 está disponível em <http://www.pnud.org.br/atlas/ ranking/Ranking-IDHM-Municipios-2010.aspx>. Acessado em 28 nov. 2014.

As condicionalidades são estabelecidas nas áreas dos serviços de saúde, educação e assistência social. De acordo com o MDS (Ministério do Desenvolvimento Social e de Combate à Fome), "na área de saúde, as famílias beneficiárias assumem o compromisso de acompanhar o cartão de vacinação e o crescimento e desenvolvimento das crianças menores de 7 anos. As mulheres na faixa de 14 a 44 anos também devem fazer o acompanhamento e, se gestantes ou nutrizes (lactantes), devem realizar o pré-natal e o acompanhamento da sua saúde e do bebê. Na educação, todas as crianças e adolescentes entre 6 e 15 anos devem estar devidamente matriculados e com frequência escolar mensal mínima de 85\% da carga horária. Já os estudantes entre 16 e 17 anos devem ter frequência de, no mínimo, 75\%. Na área de assistência social, crianças e adolescentes com até 15 anos em risco ou retiradas do trabalho infantil pelo Programa de Erradicação do Trabalho Infantil (PETI) devem participar dos Serviços de Convivência e Fortalecimento de Vínculos (SCFV) do PETI e obter frequência mínima de 85\% da carga horária mensal." Disponível em: <http://www.mds.gov.br/bolsafamilia/condicionalidades>. Acessado em 30 set. 2012. 
Considerando o formato familista e maternalista do PBF, nossas investigações interrogam como as beneficiárias conciliam trabalho remunerado e cuidados com a família, os obstáculos enfrentados para o exercício dessa conciliação e os possíveis impactos positivos e negativos para a situação delas, com vistas à redução das desigualdades de gênero. No decorrer do processo de desenvolvimento da presente análise, levamos em conta a existência ou não de avanços no que diz respeito ao compartilhamento de tarefas de cuidados domésticos com outros membros familiares ou se o próprio PBF resulta em ocorrência de maior sobrecarga de tarefas para as mulheres titulares.

\section{A estrutura de gênero no contexto familiar: subordinação das mulheres}

Se olhamos a sociedade moderna sob a perspectiva da configuração da sociedade industrial, os caracteres de gênero encontram-se presentes no cerne de sua organização. Conforme Ulrich Beck (2010, p. 161), "sem a distinção dos papéis de mulheres e homens, não haveria família nuclear. Sem família nuclear, não haveria sociedade industrial em seu esquematismo de vida e trabalho". Desse modo, a base da sociedade moderna é o resultado de um tipo de equação entre papéis de gênero, família nuclear e sociedade industrial. $\mathrm{O}$ "esquematismo de vida e trabalho", a que Beck se refere, diz respeito também à organização de certos tipos de proteção social que foram teorizados por Esping-Andersen (1991) sob a nomenclatura do Estado de bem-estar social. Para esse autor, a combinação entre Estado, mercado e família em vista da proteção social é um dos princípios do direito social. Em consequência, é também um dos critérios para a tipificação dos regimes de bem-estar. Em trabalho posterior, ao acolher as críticas feministas, Esping-Andersen (1995) também destacou os efeitos diferenciais que essa combinação produziu para mulheres e homens. Entre as tentativas de respostas à crise do Estado de bem- estar social, encontram-se as experiências bastante difundidas de ampliação da participação das mulheres no trabalho remunerado. A taxa de emprego feminino tornou-se, então, um dos fatores diferenciais para os ajustes dos regimes de bem-estar e, nesses contextos, o que se destaca é a importância de se oferecerem condições às mulheres "para compatibilizar os objetivos da família e os do trabalho" (Esping-Andersen, 1995, p. 80).

A proteção social aos indivíduos, como já vimos alertando, não pode ser explicada apenas com o olhar genérico para as políticas de bem-estar e 
desenvolvimento. Na medida em que a família nuclear foi historicamente um dos pilares do Estado de bem-estar social e considerando que o gênero é um elemento constitutivo da organização familiar, a clássica dualidade entre "homem provedor" e "mulher cuidadora" produziu formas sexualmente diferenciadas de acesso aos direitos e benefícios, resultando no que Carole Pateman (2000) denominou de "Estado de bem-estar social patriarcal".

A estrutura de gênero na família, com a correspondente subordinação das mulheres, articula-se com a estrutura generificada da proteção social e com o mercado de trabalho também estruturado por gênero, o que se expressa na "vinculação persistente da mulher ao trabalho precário" (Campos e Teixeira, 2010, p. 20). Em termos de seguridade social, o que se produz é uma estrutura vinculada aos sistemas de gênero com a seguinte lógica: os benefícios vinculados ao trabalho são em sua maioria destinados aos homens; os benefícios vinculados à renda familiar são em sua maioria destinados às mulheres (Fraser, 1999; Pateman, 2000). Desse modo, Pateman propõe que as pesquisas feministas devem se preocupar tanto com a importância das mulheres para o Estado de bem-estar como com a importância do Estado de bem-estar para as mulheres. Nesse aspecto, "as políticas de Estado de bem-estar têm garantido de várias maneiras que as mulheres/esposas proveem os serviços de bem-estar de forma gratuita, disfarçados como parte de sua responsabilidade na esfera privada" (Pateman, 2000, p. 13; tradução nossa). Como consequência, produz-se um paradoxo na lógica dessas políticas, pois:

[...] as mulheres devem dar bem-estar a outros e cuidar de si mesmas, e, portanto,
deve-se presumir que elas têm as capacidades necessárias para essas tarefas. No
entanto, o desenvolvimento do Estado de bem-estar também tem pressuposto que
as mulheres necessitam de proteção e são dependentes dos homens (Pateman, 2000,
p. 14; tradução nossa).

Quanto às formas de participação das mulheres no Estado de bem-estar, Pateman (2000) identifica três tipos principais: (i) como força de trabalho para o Estado de bem-estar, (ii) como receptoras de benefícios, e (iii) como negociadoras com o Estado. Em todas essas formas de participação, o cuidado é um fator decisivo para o posicionamento das mulheres. A participação dos homens, todavia, é destacada em outros três tipos de atividades: (i) na formulação da legislação, (ii) na administração do Estado, 
e (iii) no desenho das políticas. De acordo com Pateman, essa situação é também ilustrativa da base sexualmente diferenciada da incorporação de mulheres e homens como cidadãs e cidadãos e da constituição do Estado de bem-estar. Subjacente a essa lógica sexualmente diferenciada do bem-estar, encontra-se o fato de que a pobreza tem sexo e, no caso brasileiro, tem sexo e cor, o que exige um olhar que articule gênero e raça/etnia (Melo, 2005; Pinheiro et al., 2008; Ipea, 2011).

O Brasil, sem a mesma força dos trabalhadores nos conflitos derivados das relações de trabalho e inserido nas condições de um país de capitalismo periférico, vivenciou diferentemente o "Estado social". Refletindo particularmente sobre o caso latino-americano e brasileiro, Lena Lavinas (2004, p. 67) considera:

É notório que o sistema de proteção social latino-americano jamais se constituiu verdadeiramente num welfare, embora tenha se inspirado no modelo europeu nas suas origens, tomando os mesmos valores de solidariedade e coesão social. O Brasil não é exceção nessa matéria. De cunho corporativista-meritocrático, voltado aos segmentos formais da economia, nosso sistema de proteção social se caracteriza por ainda oferecer cobertura restrita, atendendo a uma parcela reduzida da população, da qual as pessoas pobres sempre foram, de fato, excluídas em razão dos seus vínculos instáveis e precários com o mercado de trabalho. Não sendo um grupo de pressão, sem posição sócio-ocupacional definida, as camadas pobres da população jamais foram sistemática e regularmente beneficiadas, e seu atendimento sempre foi justificado como um ato humanitário ou uma moeda política.

O contexto de expansão da globalização econômica e das políticas neoliberais de ajuste no decorrer da década de 1990 lançaram, portanto, especificidades para o caso latino-americano, incluindo o Brasil, em face da inexistência de um sistema consolidado de proteção social. O que caracteriza a perspectiva neoliberal, de acordo com Anete Brito Leal Ivo (2004, p. 59), é a "distensão da relação entre proteção social e emprego, rompendo o modelo que caracterizou a construção do Estado social". Para Maxine Molyneux (2007), entretanto, é inadequado definir os períodos recentes das políticas sociais na América Latina como "enfoque neoliberal", uma vez que as reformas têm absorvido a linguagem da igualdade, da cidadania e da participação, e os gastos sociais apresentam expansão, ainda que insuficiente. 
Enquanto a crise do emprego era menos sentida, os programas de combate à pobreza, nos países da América Latina, recorriam ao sistema de "recursos da pobreza" como estratégia de ação. Os "recursos da pobreza" referiam-se à capacidade das famílias em se adaptar às mudanças econômicas e ao arrocho salarial mobilizando outras fontes de renda, aumentando as horas de trabalho e ocupando mais membros da família, sobretudo as mulheres, em atividades remuneradas. Em síntese, tratava-se da intensificação do uso da força de trabalho (González de la Rocha, 2004).

Mercedes González de la Rocha (2004) considera que a ideia de "recursos da pobreza", após a expansão da globalização e do neoliberalismo dos anos de 1990, deve ceder espaço para a "pobreza de recursos", no sentido de que hoje a pobreza se acentua com a escassez de possibilidades de intensificação do uso da força de trabalho. Para pensarmos particularmente no caso das mulheres pobres nos países em desenvolvimento, enquanto foi possível vigorar a estratégia de mobilização dos "recursos da pobreza", muitas vezes isso significava o uso do trabalho feminino em atividades remuneradas, em casa ou fora dela, ou ampliação de jornada de trabalho para aquelas que já eram ocupadas. $\mathrm{Na}$ ausência de equipamentos sociais como creche e escola em período integral, mobilizar esses recursos da pobreza invariavelmente produzia o efeito de sobrecarregar as atividades das mulheres. Ou seja, os recursos da pobreza, muitas vezes, eram um outro modo de referência às mulheres.

Se intensificar o uso da força de trabalho dos membros da família era basicamente a única forma de se proteger da pobreza, como ficam as condições das mulheres pobres quando se lançam mais fortemente no mercado de trabalho sem a devida proteção relativa aos serviços de cuidado? Elizabeth Jelin (1995) analisa interrogação semelhante com base na reflexão sobre a importância das políticas públicas para a garantia dos direitos humanos, especialmente das mulheres, considerando que estas assumem a execução de tarefas domésticas e/ou comunitárias de atividades que deveriam ser direitos sociais providos como serviços públicos. Trata-se de tarefas reprodutivas que têm função social. Como afirma Jelin (1995, p. 392; tradução nossa):

Falar da necessidade de encarar as tarefas reprodutivas cotidianas como parte das políticas públicas implica basicamente reconhecer que as tarefas da reprodução cotidiana da população, essas tarefas historicamente invisíveis e "privadas", não podem seguir tomadas como dadas, considerando-as como supostas. 
Tratar da condição das mulheres para a conciliação entre trabalho remunerado e vida familiar exige, portanto, uma perspectiva sintonizada com o contexto da pobreza nos países em desenvolvimento, contexto esse marcado por políticas familistas, como é o caso brasileiro. Por familismo, entendemos as políticas e ações que substituem a preocupação com o empoderamento das mulheres pela defesa de políticas que reforçam a família. Uma característica dessas políticas é a referência à pobreza sem qualquer ligação com a crítica à subordinação feminina (Jelin, 2005). Essas políticas são também maternalistas no sentido de que o acesso das mulheres aos direitos sociais está condicionado por sua situação de esposa e mãe (Molyneux, 2007).

Tomando por base as medições do Índice de Desenvolvimento $\mathrm{Hu}$ mano (IDH), Martha Nussbaum (2002, p. 29; tradução nossa) reitera a constatação de que "não há país algum que trate sua população feminina de maneira igual à masculina", fenômeno esse que resultou na formulação de índices que possam mensurar as desigualdades de gênero. Ainda que a desigualdade de gênero seja um fenômeno universal, "os países em desenvolvimento apresentam problemas de especial urgência”, uma vez que "as desigualdades entre os sexos estão em forte correlação com a pobreza. Quando a pobreza se combina com a desigualdade dos sexos, o resultado é uma aguda carência das capacidades humanas centrais" (idem, ibidem; tradução nossa).

Se o desenvolvimento do Estado de Bem-Estar Social conviveu e convive com as chamadas demandas pós-materialistas, as mulheres dos países em desenvolvimento, especialmente aquelas em situação de pobreza, mobilizam um repertório distinto para suas reivindicações, abarcando temas como "a fome e a nutrição, a alfabetização, os direitos sobre a terra, o direito de acesso ao trabalho extradomiciliar, o matrimônio infantil e o trabalho infantil" (Nussbaum, 2002, p. 35; tradução nossa). Nesses contextos, a realização da autonomia das mulheres exige uma inversão da lógica das políticas de combate à pobreza e políticas de desenvolvimento: frequentemente, elas tratam as mulheres "como meros instrumentos para os fins dos outros" (idem, p. 28; tradução nossa), o que envolve sua oferta de cuidado. O enfoque defendido por Nussbaum exige que as mulheres sejam consideradas "como um fim em si mesmas, como pessoas com dignidade que merecem respeito por parte das leis e das instituições". 


\section{Mulheres brasileiras em contexto de pobreza: trabalho remunerado e desigualdades de gênero}

As distribuições das "responsabilidades de enfrentamento dos riscos sociais entre Estado, mercado e família" (Campos e Teixeira, 2010, p. 21) apresentam-se diferentemente em virtude das desigualdades entre classes sociais e grupos étnico-raciais. As intersecções de gênero, classe e raça/ etnia, portanto, são promissoras para a compreensão das condições das mulheres pobres na conciliação entre trabalho remunerado e vida familiar. A ocorrência concomitante dos "aspectos de gênero da discriminação racial" e dos "aspectos raciais da discriminação de gênero" (Crenshaw, 2002, p. 173) constitui o que estamos considerando como "discriminação interseccional" (Crenshaw, 2002), diante da qual as mulheres negras tendem a apresentar maior vulnerabilidade social que as mulheres não negras.

De acordo com o Retrato das desigualdades de gênero e raça (Ipea, 2011), a população negra representava $51,1 \%$ da população brasileira, enquanto, no Programa Bolsa Família, 70\% dos domicílios atendidos eram chefiados por negros(as). As mulheres compreendiam, no mesmo ano, 51,3\% da população brasileira, e 35,2\% dos domicílios eram chefiados por elas. Os homens brancos formam o grupo com melhores condições de proteção social, enquanto as mulheres negras formam o grupo menos protegido socialmente. Quanto ao mercado de trabalho, "em 2009, a taxa de participação das mulheres com mais de 16 anos era de 58,9\%, enquanto a dos homens era de 81,6\%" (Ipea, 2011, p. 27). "O desemprego é também uma realidade permeada de desigualdades de gênero e raça": os homens brancos apresentam a menor taxa, enquanto as mulheres negras apresentam a maior taxa (idem, ibidem). Os dados do Retrato das desigualdades de gênero e raça apontam que

[...] as mulheres têm consolidado, ao longo das últimas décadas, sua participação no mercado de trabalho no Brasil, que deixa, aos poucos, de ser percebida como secundária ou intermitente. A inserção das mulheres nesta realidade é, no entanto, marcada por diferenças de gênero e raça. Além de estarem menos presentes do que os homens no mercado de trabalho, ocupam espaços diferenciados, estando sobrerrepresentadas nos trabalhos precários. Ademais, a trajetória feminina rumo ao mercado de trabalho não significou a redivisão dos cuidados entre homens e mulheres, mesmo quando se trata de atividades remuneradas, o que pode ser percebido pela concentração de mulheres, especialmente negras, nos serviços sociais e domésticos (Ipea, 2011, p. 27). 
No que se refere ao grupo de pesquisa (190 entrevistadas), em Curitiba, $35 \%$ eram brancas e $65 \%$ não brancas; em Fortaleza, 13\% eram brancas e $87 \%$ não brancas. A faixa de idade entre 30 e 39 anos concentra o maior grupo em Curitiba, com 37\%; 31,5\% de jovens entre 15 a 29 anos e outras $31,5 \%$ com 40 anos ou mais de idade. Em Fortaleza, as entrevistadas tinham em média mais idade, comparadas às de Curitiba: 12,6\% entre 20 e 29 anos; $36,6 \%$ entre 30 e 39 anos e 50,6\% com 40 anos ou mais de idade. Em síntese, o grupo mais jovem é menos representativo em Fortaleza, e o grupo com 40 anos ou mais de idade é o maior. A escolaridade é também uma variável com baixo resultado e com desempenho um pouco melhor em Curitiba: em Fortaleza, $77 \%$ das entrevistadas estudaram até a $8^{\text {a }}$ série (ensino fundamental completo); em Curitiba, 68\% estudaram até esse mesmo nível.

No total de 190 beneficiárias entrevistadas, há uma divisão relativamente parelha entre as titulares do PBF com atividade remunerada (47\%) e aquelas sem atividade remunerada (53\%), como se verifica no Gráfico 1.

Gráfico 1 - Respondentes com atividade remunerada em Curitiba e Fortaleza

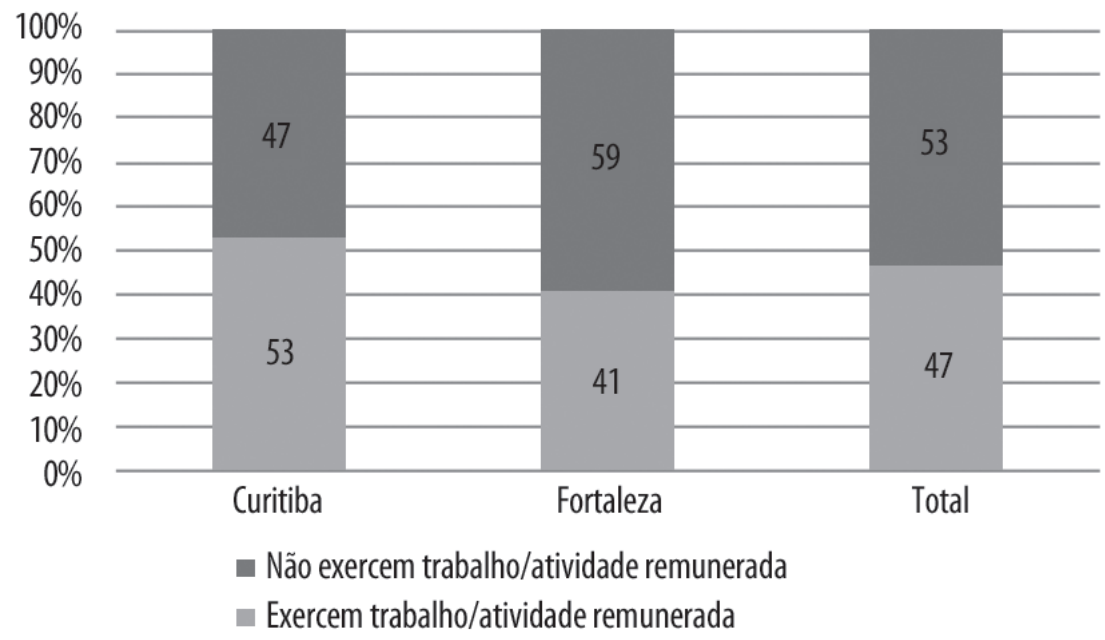

Fonte: Elaboração própria.

Comparando-se com a taxa nacional de participação das mulheres no mercado de trabalho (58,9\%), observa-se, pela média de nossa amostra (47\%), 
que as mulheres pobres têm menor acesso ao mercado de trabalho. No entanto, considerando-se o histórico de participação dessas mesmas mulheres no mercado de trabalho, constata-se que essa menor participação não pode ser imputada a possíveis efeitos da transferência de renda. Interpretamos, então, que o PBF não desincentiva o trabalho, mas também não o incentiva. De um lado, esses resultados colocam em suspenso as críticas dirigidas à transferência de renda com base no temor de que ela produziria o "efeito preguiça" ou o desincentivo ao trabalho ${ }^{4}$. Por outro lado, não respondem aos anseios de autonomia feminina vocalizados pelas feministas.

Quando nos referimos ao trabalho remunerado, há um aspecto normativo em nossa análise, implícito até o presente momento, que deve ser evidenciado: a participação no trabalho remunerado é um aspecto fundamental para a constituição da cidadania e das identidades, portanto de autonomia, em uma sociedade de mercado (Castel, 1998; Pateman, 2000; Oliveira, 2006). Em conformidade com Pateman (2000, p. 12; tradução nossa):

Se um indivíduo pode obter reconhecimento de outros cidadãos como um cidadão igualmente valioso tão somente através da participação no mercado capitalista, se o autorrespeito e o respeito enquanto cidadão é "alcançado" na esfera pública da sociedade do emprego, então, as mulheres [quando não participantes do trabalho remunerado] carecem dos meios para ser reconhecidas como cidadãs valiosas.

As questões que estamos apontado são diretamente afetas à temática do desenvolvimento humano e mereceram a atenção das feministas para o exame das ações empreendidas nos países em desenvolvimento e do nexo entre gênero e pobreza. De acordo com Nussbaum (2002, p. 27; tradução nossa):

As mulheres carecem de apoio em funções fundamentais da vida humana na maior parte do mundo. Elas são piores alimentadas do que os homens, têm um padrão mais baixo de saúde, são mais vulneráveis à violência física e ao abuso sexual. É muito menos provável que sejam alfabetizadas, e ainda menos provável que tenham educação profissional ou técnica. Se elas tentam acessar um emprego, enfrentam obstáculos maiores, incluindo a intimidação por parte da família ou do marido, discriminação salarial por seu sexo e assédio sexual no local de trabalho. E tudo isso sem recursos legais efetivos para se defender. Barreiras similares muitas vezes lhes impedem a participação efetiva na vida política.

Sobre essas críticas, ver, por exemplo: Esping-Andersen (1995), Tavares (2010), Brito (2011) e Teixeira (2011). 
Por meio de survey realizado em mais de setenta países, Ronald Inglehart e Pippa Norris (2003) investigaram as variáveis que interferem nas atitudes igualitárias relativas aos papéis de homens e mulheres e constataram que ter cônjuge interfere negativamente nas posições de gênero mais igualitárias. Ter mais idade, frequentar uma religião e ter filhos também apresentam esse resultado negativo. Por outro lado, a escolaridade e a participação no mercado de trabalho são variáveis que se correlacionam positivamente com as posições de gênero mais igualitárias. Os autores estão de acordo quanto à importância do crescimento econômico e das reformas legais para promover a igualdade de gênero, contudo, acrescentam a tese de que a cultura importa.

De forma análoga, nossa pesquisa demonstra que a presença do cônjuge é uma variável que interfere negativamente na participação das mulheres no trabalho remunerado. Para tratar da situação de conciliação entre trabalho remunerado e cuidado, selecionamos a subamostra exclusivamente composta pelas entrevistadas que declaram a presença em trabalho remunerado. Essa subamostra é formada por 89 entrevistadas, sendo 50 de Curitiba e 39 de Fortaleza (Gráfico 2).

Gráfico 2 - Presença de cônjuge entre as respondentes com trabalho remunerado em Curitiba e Fortaleza

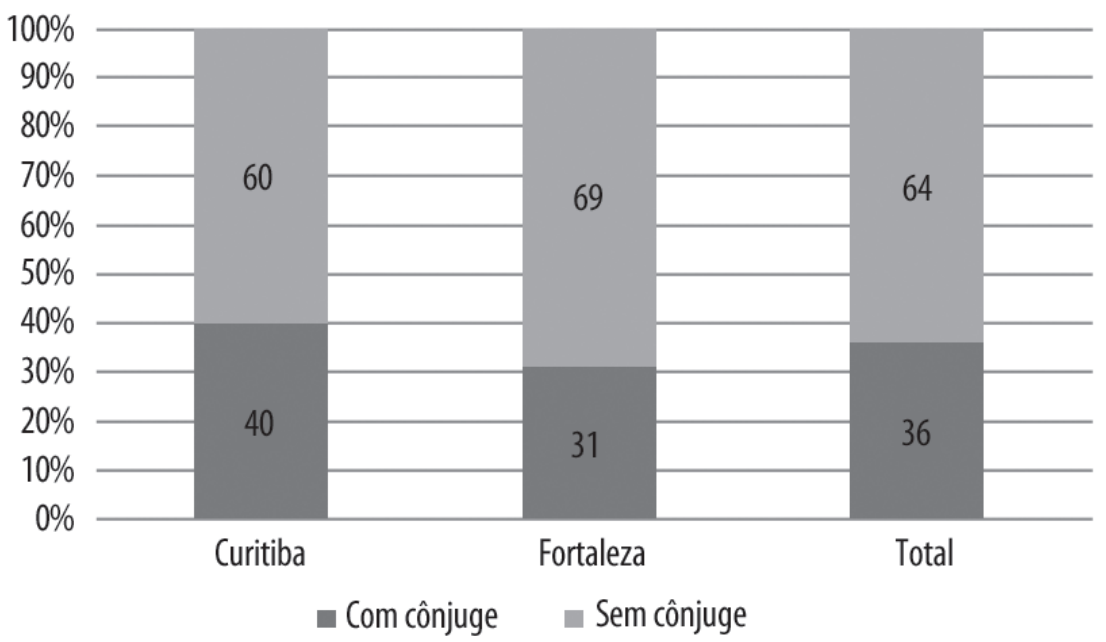

Fonte: Elaboração própria. 
Conforme os dados desse gráfico, a maioria das mulheres com trabalho remunerado forma grupos domésticos sem a presença de cônjuge (64\%), fenômeno um pouco mais acentuado em Fortaleza (69\%) do que em Curitiba (60\%). Tais dados são indicativos de que a presença de cônjuge inibe a participação das mulheres em atividades econômicas, e mostram a persistência da dualidade dos papéis tradicionais baseados no "homem provedor" e "mulher cuidadora" (Pateman, 2000), o que Cynthia Sarti (2005) também denominou de "ética do provedor", em distinção à ética do trabalho como vocação presente nos estudos de Max Weber.

Essa divisão de papéis de gênero está baseada na divisão sexual do trabalho. Tomando como referência Danièle Kergoat (2009), vale lembrar que essa noção foi primeiro utilizada pelos etnólogos como uma repartição "complementar" das tarefas realizadas entre os homens e as mulheres nas respectivas sociedades que lhes interessavam como objeto de investigação. Claude Lévi-Strauss (apud Kergoat, 2009), por exemplo, refletiu sobre a divisão sexual do trabalho tomando-a como uma maneira explicativa de estruturação da sociedade em família. Kergoat destaca, porém, o avanço teórico das antropólogas feministas nas reflexões sobre a divisão sexual do trabalho, tendo em conta que esta passa a ser vista como uma noção que "traduz uma relação de poder dos homens sobre as mulheres” (Kergoat, 2009, p. 66). Assim, a divisão sexual do trabalho configura-se num conceito analítico para uma pluralidade de disciplinas que compõem as ciências humanas. A concepção mais específica de Kergoat sobre a divisão sexual do trabalho resulta no seu entendimento como "a forma de trabalho social decorrente das relações sociais de sexo; essa forma é historicamente adaptada a cada sociedade" (Kergoat, 2009, p. 67).

Para um melhor exame sobre esse tema, investigamos também os motivos que justificam, na opinião das entrevistadas, a participação das mulheres no trabalho pago extradomiciliar (Tabela 1). A fim de captar mais precisamente as percepções associadas à conciliação entre trabalho remunerado e vida familiar, a pergunta formulada questionava os motivos justificadores das mulheres casadas e com filhos exercerem trabalho pago. 
Tabela 1 - Motivos que justificam o exercício de trabalho remunerado entre as mulheres casadas e com filhos(as), na opinião das respondentes com trabalho remunerado em Curitiba e Fortaleza

\begin{tabular}{c|c|c|c|c|c|c}
\hline \multirow{2}{*}{ motivos } & \multicolumn{2}{|c|}{ Curitiba } & \multicolumn{2}{c|}{ Fortaleza } & \multicolumn{2}{c}{ total } \\
\cline { 2 - 7 } & $\mathrm{f}$ & $\%$ & $\mathrm{f}$ & $\%$ & $\mathrm{f}$ & $\%$ \\
\hline necessidade financeira da família & 22 & 43 & 35 & 47 & 57 & 45 \\
\hline realização de algum projeto familiar & 1 & 2 & 12 & 16 & 13 & 10 \\
\hline realização pessoal & 4 & 8 & 7 & 9 & 11 & 9 \\
\hline independência econômica da mulher & 21 & 41 & 15 & 20 & 36 & 29 \\
\hline não ficar limitada à casa & 3 & 6 & 6 & 8 & 9 & 7 \\
\hline total & 51 & 100 & 75 & 100 & 126 & 100 \\
\hline
\end{tabular}

Fonte: Elaboração própria.

Nota: Pergunta com respostas múltiplas.

Essas opiniões nos permitem inferências sobre o peso dos valores associados aos papéis tradicionais de gênero. No conjunto das 89 entrevistadas com trabalho remunerado, $55 \%$ das respostas obtidas indicam que esses motivos estão associados às necessidades ou aos interesses da família, enquanto os outros $45 \%$ das respostas agregam motivos que remetem à individualização da mulher. Observa-se que essa noção de individualização é minoritária, ainda que a diferença entre os dois grupos de respostas não seja tão díspar. Esses dados corroboram resultados de pesquisas que constataram as percepções de que o trabalho feminino é visto como auxiliar (Bruschini, 1990; Sarti, 2005). Clara Araújo e Celi Scalon (2006) também chegaram a resultados semelhantes em pesquisa sobre gênero, trabalho e família no Brasil realizada com amostra nacional, por meio de survey, no ano de 2003. Para as autoras, o que talvez mereça destaque é a permanência ainda forte desses valores, $o$ trabalho feminino como auxiliar, em um contexto de elevada participação das mulheres na população economicamente ativa.

Esse é um fator com significativa diferença entre as duas capitais pesquisadas. Em Curitiba, os motivos associados aos interesses ou projetos familiares para o trabalho remunerado das mulheres envolvem $45 \%$ e, a maioria, 55\% das respostas, invoca ideias relativas à individualização da mulher. Em Fortaleza, a situação se inverte e a dimensão familiar abarca aproximadamente dois terços das respostas, diante de um pouco mais de um terço que invoca a individualização da mulher. Esses dados sugerem que em uma cidade como 
Curitiba, com mais avanços em termos de desenvolvimento social e com mais oportunidades de trabalho remunerado para as mulheres em situação de pobreza, existem mais possibilidades para a emergência de percepções que consideram o trabalho remunerado como forma de individualização feminina, contribuindo para um relativo descolamento entre o trabalho da mulher e o cumprimento dos papéis sociais que atam as mulheres aos interesses dos grupos domésticos. As diferenças entre Curitiba e Fortaleza são consistentes com uma versão revisada da teoria da modernização, de acordo com a qual "o desenvolvimento humano possibilita mudanças culturais de atitudes para a igualdade de gênero" (Inglehart e Norris, 2003, p. 10; tradução nossa).

Conforme Kergoat (2009) já registrou, uma característica básica da divisão sexual do trabalho é a tradicional visão cristalizada sobre a prioridade masculina quanto à esfera produtiva e a associação das mulheres à esfera reprodutiva. Por outro lado, existem outras formas cristalizadas de associação de gênero, seja no caso das mulheres em relação à esfera privada ou dos homens quanto à ocupação das funções de valores sociais mais elevados, tais como funções políticas, religiosas, militares, entre outras. Kergoat, ainda que procure ponderar acerca da divisão sexual do trabalho, ao apontar para o fato de que esta não é um dado rígido e imutável - afinal, os avanços históricos nos processos de luta contra as desigualdades de gênero não podem ser ignorados -, ressalta a segregação do trabalho por gênero (ocupações entendidas como predominantemente "masculinas" ou "femininas") e a hierarquização, que resultam na maior valorização do trabalho masculino em relação ao trabalho feminino, como dois princípios ordenadores da divisão sexual do trabalho.

O caráter histórico e contextual das configurações da divisão sexual do trabalho em diversas sociedades é fortemente evidenciado no contexto brasileiro e tem levado diversas autoras e autores a repensar as mudanças nas relações entre os sexos e a questionar concepções hegemônicas de masculinidade e feminilidade, supostamente presentes na sociedade. Porém, considerando a base patriarcal sobre a qual historicamente se assentou a sociedade brasileira, é possível compreender (o que não significa conformar-se) a permanência de uma visão tradicional acerca das configurações de gênero.

Nesse sentido, os dados que dizem respeito à distribuição das tarefas relacionadas ao domicílio das beneficiárias do PBF, de Curitiba e de For- 
taleza, que foram entrevistadas, sustentam a afirmação da permanência de uma tradicional divisão sexual do trabalho, conforme os dados da Tabela 2.

Tabela 2 - Distribuição das tarefas relacionadas ao domicílio entre as respondentes com trabalho remunerado - Curitiba e Fortaleza (\%)

\begin{tabular}{|c|c|c|c|c|c|c|c|c|}
\hline \multirow[b]{2}{*}{ tarefas } & \multicolumn{8}{|c|}{ pessoa responsável pela tarefa } \\
\hline & $\begin{array}{l}\text { somente a } \\
\text { respondente }\end{array}$ & cônjuge & casal & $\begin{array}{l}\text { outra pessoa } \\
\text { da família }\end{array}$ & $\begin{array}{c}\text { respondente } \\
\text { e os } \\
\text { filhos(as) }\end{array}$ & $\mathrm{ns} / \mathrm{nr}$ & nsa & total \\
\hline $\begin{array}{c}\text { lavar e/ } \\
\text { ou passar a } \\
\text { roupa }\end{array}$ & 79 & 0 & 3 & 6 & 11 & 1 & 0 & 100 \\
\hline lavar a louça & 54 & 2 & 3 & 18 & 22 & 0 & 0 & 100 \\
\hline $\begin{array}{l}\text { ir ao banco / } \\
\text { lotérica pagar } \\
\text { as contas }\end{array}$ & 69 & 10 & 4 & 11 & 4 & 1 & 0 & 100 \\
\hline $\begin{array}{c}\text { pequenos } \\
\text { consertos na } \\
\text { casa }\end{array}$ & 37 & 27 & 1 & 22 & 2 & 8 & 2 & 100 \\
\hline limpar a casa & 67 & 1 & 3 & 11 & 17 & 0 & 0 & 100 \\
\hline cozinhar & 78 & 2 & 1 & 6 & 13 & 0 & 0 & 100 \\
\hline
\end{tabular}

Fonte: Elaboração própria.

Nota: Pergunta com respostas múltiplas.

As respondentes da pesquisa, mesmo sendo mulheres com atividade remunerada no mercado de trabalho, são as principais responsáveis por todas as tarefas domésticas sobre as quais foram inquiridas, o que evidencia a ocorrência da conciliação entre trabalho remunerado extradomiciliar e atividades domésticas em benefício do grupo familiar. O cuidado com as roupas e o preparo de alimentos são as principais tarefas assumidas por essas mulheres, seguidas de perto pelas tarefas de limpeza da casa e de sair de casa para realizar o pagamento de contas. Lavar a louça é uma atividade predominantemente assumida por essas respondentes, mas que, no entanto, conta com alguma divisão entre as demais pessoas que constituem o grupo doméstico, notadamente entre filhos(as) ou outra pessoa da família. Os pequenos consertos na casa são atividades menos desempenhadas pelas respondentes, mas, ainda assim, elas são as principais responsáveis. O cônjuge tem baixíssima participação no desempenho das atividades 
domésticas e a principal tarefa assumida por ele são os pequenos consertos na casa, ainda que em menor grau em relação às mulheres respondentes. Os filhos e as filhas compartilham com as respondentes especialmente as tarefas de lavar louças, limpar a casa, cozinhar e cuidar das roupas. No entanto, essa participação aparece com taxas muito baixas. Ainda que os nossos dados não nos permitam a desagregação por sexo, supomos que as filhas sejam as principais colaboradoras nessas tarefas. Portanto, essas mulheres em situação de pobreza, com conciliação de trabalho remunerado e cuidados familiares, encontram pouca colaboração dos demais membros do grupo familiar na realização das tarefas domésticas. Esse padrão de divisão das tarefas domésticas, ou mais precisamente de concentração dessas tarefas, é, mais uma vez, semelhante à pesquisa nacional analisada por Clara Araújo e Celi Scalon (2006), mesmo que a nossa amostra seja circunscrita às mulheres em situação de pobreza.

A divisão das tarefas domésticas impacta diretamente o uso do tempo por mulheres e homens. Nesse sentido, é importante observar a tendência similar de tais resultados com aqueles que têm sido apresentados pelas pesquisas de uso do tempo realizadas no Brasil, em particular quando se referem à relação entre as dimensões temporal e de gênero. Uma pesquisa realizada por Neuma Aguiar (2001), na Região Metropolitana de Belo Horizonte, Minas Gerais, resultou em um importante banco de dados que revela a forte tendência entre as mulheres de dedicação de mais tempo ao trabalho de cuidados com a casa e a família em relação aos homens, mesmo considerando as mulheres que exercem trabalho remunerado fora de casa ${ }^{5}$.

Reiteradamente, as pesquisas comprovam as barreiras para a redução do trabalho doméstico ou de cuidado das mulheres por meio da redistribuição desse trabalho com os demais membros do grupo doméstico. É por essa razão que Elizabeth Jelin $(1995,2005)$ destaca a importância estratégica dos serviços públicos para a redução da sobrecarga das tarefas consideradas femininas. $\mathrm{O}$ acesso a serviços públicos nos parece o modo mais factível de favorecer, para

Numa análise comparada sobre o uso do tempo em duas metrópoles brasileiras (Belo Horizonte e Rio de Janeiro), Aguiar observa que em trinta anos as mulheres dobraram o tempo dedicado às atividades remuneradas e passaram a alocar mais tempo à realização de atividades de compras, inferindo, daí, a evidência de que o maior acesso ao mercado de trabalho possibilitou uma mudança na alocação do tempo das mulheres nas decisões sobre as compras. Porém, conclui que a decisão sobre como administrar a casa e distribuir o dinheiro não representa um ganho de autonomia das mulheres em relação aos seus cônjuges, tendo em vista que esse ganho decisório se efetivou antes da implementação dos programas de transferência de renda (Aguiar, 2011). 
as mulheres, a conciliação entre vida familiar e trabalho remunerado. Nesse aspecto, são emblemáticas as coberturas dos serviços de educação infantil, com destaque para o atendimento às crianças de 0 a 3 anos de idade - as creches.

\section{Conciliação entre trabalho remunerado e cuidado: as responsabilidades das mulheres em situação de pobreza}

As variáveis trabalhadas até o presente momento que se relacionam com maior vulnerabilidade, como baixa escolaridade, menor participação no trabalho remunerado e maior taxa de grupos domésticos monoparentais, são mais destacadas entre as mulheres entrevistadas em Fortaleza. Diferindo desse quadro mais geral, as entrevistadas de Fortaleza apresentam menor número de filhos. Em média, são 3,8 filhos(as) por mulher em Curitiba e 3 em Fortaleza. Convivendo no mesmo domicílio são, em média, 2,8 em Curitiba e 2 em Fortaleza. Todavia, interessa-nos notadamente o número de filhos(as) em idade de creche ${ }^{6}$, em face da insuficiência da cobertura desse serviço no Brasil, considerando que, em 2009, a taxa nacional de cobertura era de 18,4\% (Ipea, 2011). Além de baixa, a cobertura se distribui desigualmente entre diferentes regiões do Brasil e entre as diferentes classes sociais, com claras desvantagens para as mulheres pobres e negras. Assim, observa-se que:

[...] embora nesses 14 anos a cobertura na idade de 0 a 3 anos tenha mais que duplicado, saindo de 7,6\%, em 1995, e alcançando 18,4\%, em 2009, ela não conseguiu atingir a metade da meta prevista no Plano Nacional de Educação, que era de 50\% até 2010. Os números são ainda mais incipientes na zona rural, onde há uma cobertura de apenas $8,9 \%$. Considerando-se as desigualdades raciais, em 2009, 20,2\% das crianças brancas entre 0 e 3 anos estavam matriculadas em creches, contra apenas 16,7\% de crianças negras (Ipea, 2011, p. 21).

Em Fortaleza, conforme o Gráfico 3, entre as mulheres com trabalho remunerado, apenas $38 \%$ delas têm criança em idade de creche (média de uma criança por mulher), enquanto em Curitiba são 52\% das entrevistadas na mesma situação (com média de 1,3 criança por mulher).

No Brasil, considera-se a faixa etária de 0 a 3 anos para o atendimento nos serviços de creche. Ver, por exemplo, documento disponível em <http://portal.mec.gov.br/seb/arquivos/pdf/Consescol/cad\%207. pdf>. Acessado em 22 nov. 2014. 
Gráfico 3 - Presença de crianças em idade de creche entre as respondentes com trabalho remunerado em Curitiba e Fortaleza

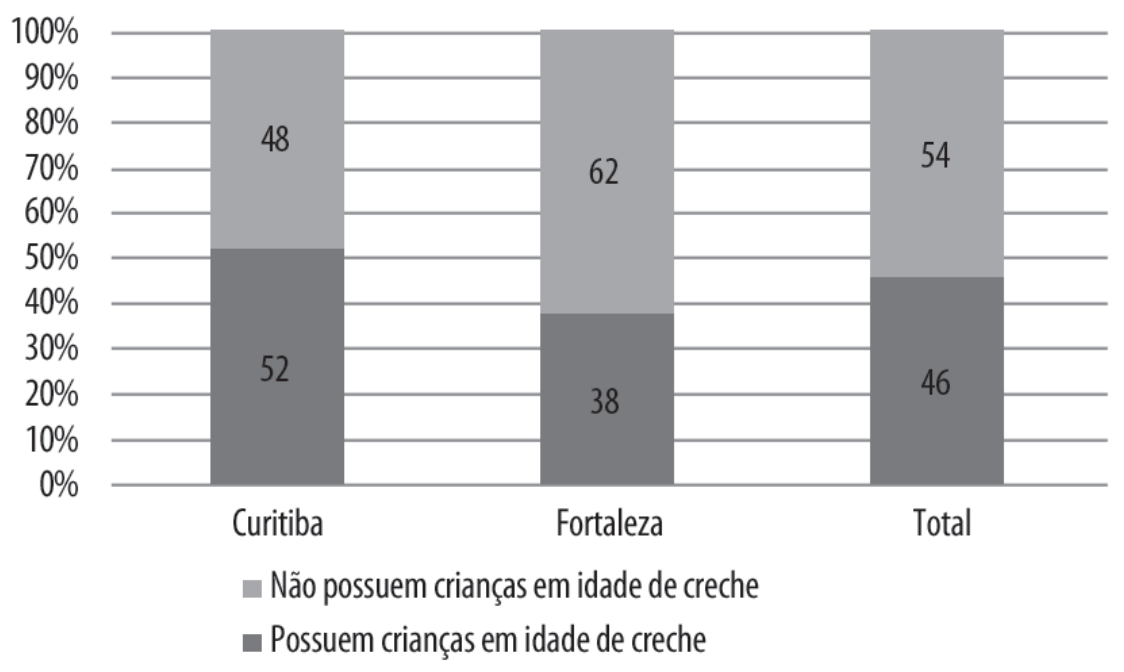

Fonte: Elaboração própria.

Entre essas mulheres com trabalho remunerado e crianças em idade de creche, em Fortaleza, 73\% delas declararam que a criança não tem acesso à creche. Em Curitiba, nas mesmas condições, essa taxa é de 35\%. Nota-se que ter criança na faixa de idade de 0 a 3 anos inibe a participação das mulheres pobres no trabalho remunerado com mais intensidade em Fortaleza, por se tratar de cidade com menor cobertura do serviço de creche.

A representação dos papéis de gênero, conforme discutimos anteriormente, juntamente com a baixa cobertura dos serviços de educação infantil, com destaque para a creche, explicam essa incidência negativa da presença das crianças no trabalho remunerado das mulheres em situação de pobreza.

A atenção à infância é um importante fator para a mensuração das atividades de cuidado exercidas pelas mulheres. Considerando tratar-se de mulheres com conciliação entre as atividades familiares e o trabalho remunerado, a literatura especializada destaca há algum tempo a importância da provisão de serviços públicos de cuidado com a infância, a fim de facilitar, para as mulheres, a conciliação entre família e mercado de trabalho (Jelin, 1995; Esping-Andersen, 1995; Lavinas, 2006). 
A baixa taxa de cobertura dos serviços de creche está associada ao reforço dos trabalhos de cuidado por parte das mulheres e ao uso, presumido, que o Estado faz do trabalho considerado feminino (Jelin, 1995; Nussbaum, 2002, 2003), disfarçando-o como parte das responsabilidades femininas privadas (Pateman, 2000), o que se intensifica com o ingresso no PBF. Cássia Carloto e Silvana Mariano $(2008,2009$ a, 2009b, 2012) analisaram a "instrumentalização do papel das mulheres" na esfera doméstica por intermédio dos programas de transferência de renda com foco na família. Segundo as autoras, "essa instrumentalização se dá fundamentalmente a partir da atuação das mulheres na esfera dos cuidados intrafamiliares, reforçando suas responsabilidades no âmbito privado doméstico" (Carloto e Mariano, 2012, p. 259). As autoras refletiram também sobre tais responsabilidades somadas a uma infraestrutura precária para a socialização dos cuidados e ao tipo exigido de qualificação profissional pelo mercado de trabalho que "contribuem para aumentar as dificuldades das mulheres em busca de sua autonomia econômica a partir do trabalho assalariado e, portanto, dificultam suas chances de sair da pobreza extrema e da condição de beneficiárias" do Programa Bolsa Família (idem, ibidem). Em suma, a imposição de condicionalidades às famílias pelo PBF gera uma sobrecarga de obrigações para as mulheres, o que tem forte impacto no modo como usam o seu tempo, "além de reforçar papéis tradicionais na esfera dos cuidados" (idem, ibidem).

Essas questões devem ser levadas em consideração quando há interesse em temas como a autonomia e o empoderamento das mulheres. Partindo de dados sobre as titulares do PBF residentes em dois municípios de porte médio - Londrina, no Paraná, e Uberlândia, em Minas Gerais -, Carloto e Mariano apontam para uma configuração tensa que emerge das necessidades de conciliação entre as esferas de cuidados intrafamiliares e do trabalho remunerado. Na percepção das mulheres que foram entrevistadas, o trabalho remunerado está diretamente relacionado às noções de autonomia e de poder. Dessa forma, complementam tal argumentação com a afirmação de que:

$\mathrm{Na}$ esteira da centralidade do trabalho (para a autonomia) [...] surgem as intersecções com a precariedade dos serviços públicos dirigidos às tarefas reprodutivas, com destaque para os serviços de atenção à infância, sendo os equipamentos de educação infantil o exemplo paradigmático. As condicionalidades do PBF produzem um aumento de responsabilidades para as titulares do benefício e não incluem em suas 
estratégias a oferta de serviços públicos para tarefas reprodutivas básicas, que tanto interferem no cotidiano das mulheres e no direito de proteção à infância (Carloto e Mariano, 2012, p. 271).

Considerando essas condições desvantajosas para a conciliação entre família e trabalho, é compreensível que a grande maioria das entrevistadas (70\%) declare que se sente com mais obrigações e responsabilidades depois da inclusão no PBF, em ambas as capitais pesquisadas, conforme mostra o Gráfico 4.

Gráfico 4 - Percepção sobre 0 aumento das responsabilidades depois do ingresso no PBF entre respondentes com atividade remunerada em Curitiba e Fortaleza

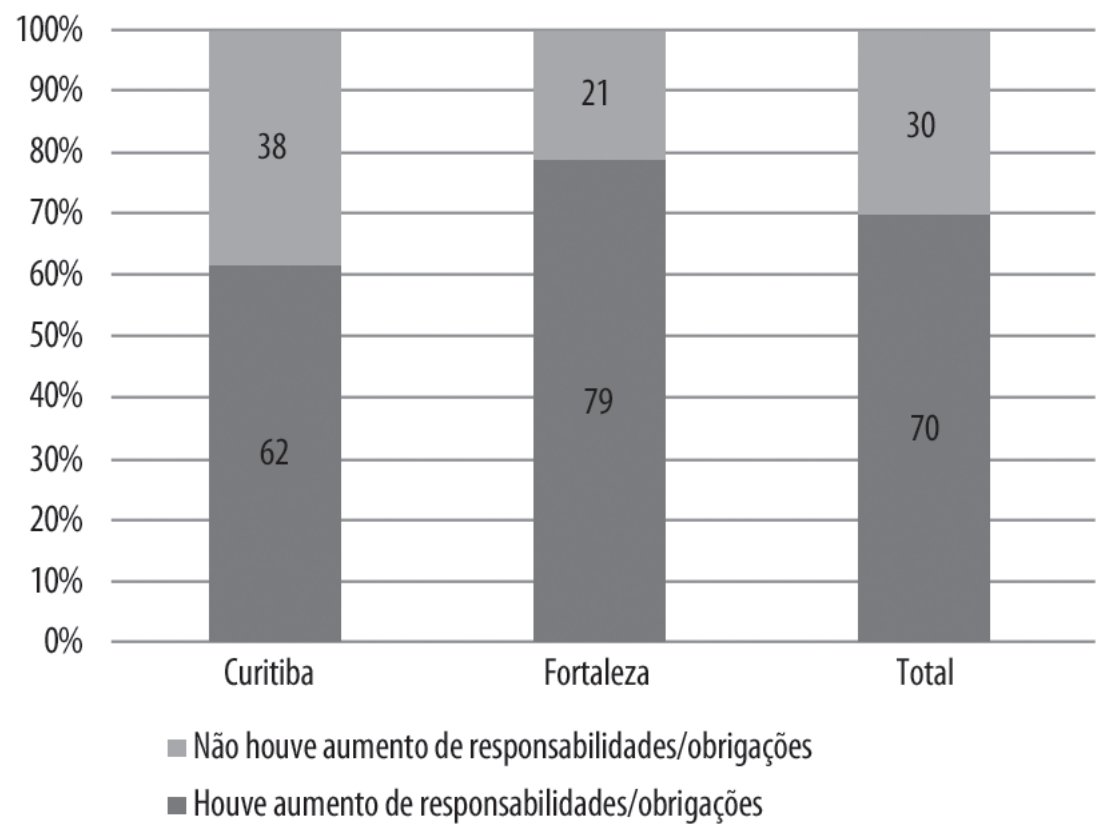

Fonte: Elaboração própria.

É importante destacar que o trabalho das mulheres voltado para o cuidado da família não envolve somente as tarefas domésticas, mas também atividades extradomiciliares, como parte das tarefas decorrentes das condicionalidades instituídas pelo PBF. 
O trabalho doméstico constitui parte das atividades reprodutivas e pode ser definido "como um conjunto de tarefas relacionadas ao cuidado das pessoas e que são executadas no contexto da família - domicílio conjugal e parentela - é trabalho gratuito realizado essencialmente por mulheres" (Fougeyrollas-Schwebel, 2009, p. 257). Considerando que nem todo trabalho de cuidado realiza-se no âmbito do espaço doméstico, Aguirre (2005) enfatiza a importância de se separar esses dois conceitos. As atividades ou o trabalho de cuidado "define um campo de problemas de pesquisa e de intervenção social com seus atores, suas instituições, suas formas relacionais, um campo que se situa na intersecção entre as famílias e as políticas sociais" (Aguirre, 2005, p. 5; tradução nossa). Ainda de acordo com a autora:

\begin{abstract}
Em termos gerais, podemos conceber o cuidado como uma atividade feminina geralmente não remunerada, sem reconhecimento nem valorização social. Compreende tanto o cuidado material como o cuidado imaterial que implica um vínculo afetivo, emotivo, sentimental. Supõe um vínculo entre quem oferece o cuidado e quem o recebe. Está baseado no relacional e não é somente uma obrigação jurídica estabelecida pela lei, mas também envolve emoções que se expressam nas relações familiares, ao mesmo tempo que contribui para constituí-las e mantê-las (Aguirre, 2005, p. 5-6; tradução nossa).
\end{abstract}

A autora classifica o cuidado em dois tipos, um deles se refere ao cuidado dedicado a crianças e adolescentes e outro ao cuidado de pessoas doentes e idosas. Para Aguirre (2005, p. 6; tradução nossa): "No caso do cuidado infantil, há uma fronteira difusa entre atividades de cuidado e as atividades próprias da educação inicial, fato pelo qual a noção de cuidados apresenta particular interesse para pôr em evidência atividades que, de outra forma, permaneceriam ocultas".

Esse é o tipo de cuidado mais encontrado no cotidiano das mulheres pobres entrevistadas e é afetado diretamente pelas condicionalidades instituídas pelo PBF. Os dados do Gráfico 4 apresentam as opiniões das mulheres, de Curitiba e de Fortaleza, sobre o fato de se sentirem com mais obrigações e responsabilidades após a inclusão como beneficiárias do PBF. Nota-se que 62\% das entrevistadas de Curitiba e 79\% das entrevistadas de Fortaleza, cidade com menor oferta de serviços de creche, sentem o aumento de obrigações e responsabilidades. Variados estudos sobre a dimensão dos cuidados com a família e com as crianças, ainda que reconheçam os avanços no que diz respeito à divisão do trabalho doméstico entre os casais, apontam para resistências às mudanças referentes à desigualdade entre os sexos na realização dessas atividades. A perspectiva de gênero é fundamental 
para a compreensão da persistência da percepção sobre a responsabilidade do cuidado com os filhos, tendo em vista que tal atividade é, em geral, entendida como a provisão diária de atenção social, física, psíquica e emocional às pessoas (Araújo e Scalon, 2005), e foi historicamente construída e "naturalizada" como um atributo feminino.

Nadya Guimarães, Helena Hirata e Kurumi Sugita (2012), em artigo intitulado "Cuidado e cuidadoras: o trabalho de care no Brasil, França e Japão", chamam a atenção para o caráter de construção social do care. Reconhecem a dificuldade em se traduzir o significado do care para diversas línguas e, nesse sentido, buscam destacar que, no léxico brasileiro, as atividades ligadas ao care (cuidar) estão firmemente arraigadas à ideia de submissão. Desse modo, argumentam que a dimensão de gênero encontra-se sempre presente, seja em referência ao care como intrínseco a certas atividades domésticas ou ao care como profissão (cuidador de crianças, de idosos, de pessoas deficientes etc.).

Nesse contexto de trabalho remunerado precário e escassez de serviços públicos que aliviem as tarefas reprodutivas das mulheres, especialmente as de cuidado, e com percepção de aumento de sua sobrecarga decorrente do PBF, quais preferências são produzidas entre essas mulheres? Os resultados de nossa subamostra encontram-se no Gráfico 5.

Gráfico 5 - Preferências entre as beneficiárias com atividade remunerada sobre a conciliação entre família e trabalho em Curitiba e Fortaleza

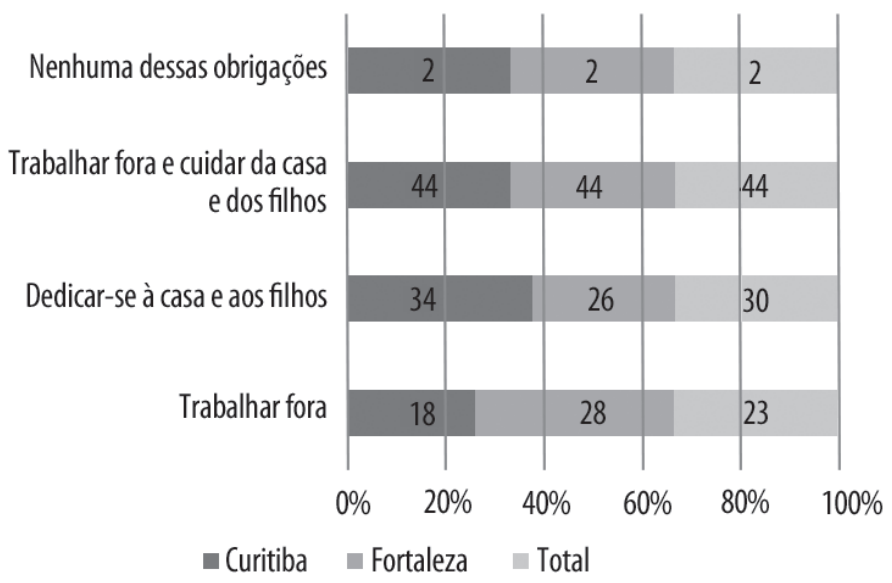

Fonte: Elaboração própria. 
Na situação hipotética de ter a condição de realizar escolhas, um pouco menos da metade dessas mulheres prefere a conciliação do trabalho remunerado com os cuidados, com percentuais idênticos nas duas cidades (44\%). No total da subamostra, $23 \%$ preferem exclusivamente o trabalho remunerado e $30 \%$ preferem a dedicação à casa e aos filhos(as). Logo, caso pudessem escolher, a maioria dessas mulheres não conviveria com a referida conciliação, o que sugere que, mais do que propriamente uma conciliação, essa é uma realidade de tensão para a maioria dessas mulheres, pobres e negras. Chama a atenção, ainda, que a preferência pelo trabalho remunerado apresenta uma frequência inferior à preferência pela dedicação à casa e a filhos(as). Esse é um indício de que a valorização da maternidade é mais comum do que a valorização da autonomia econômica. Ao analisar os resultados de pesquisa nacional sobre tema semelhante, Araújo e Scalon (2006, p. 4) consideraram que "há uma elevada aceitação do trabalho como parte constitutiva da vida da mulher [...] [e] essa aceitação é acompanhada da permanência da valorização da domesticidade feminina, particularmente de seu aspecto maternal".

Duas ponderações nos auxiliam na compreensão dessas preferências. Primeiro, devemos relativizar o suposto nexo causal entre a dimensão econômica, ou financeira, e a autonomia feminina, inclusive porque a inserção precária dessas mulheres no mercado de trabalho comprova que o trabalho não pode se traduzir em autonomia econômica para elas. Segundo, conforme Nussbaum (2002, p. 64; tradução nossa) tem alertado, "é crucial compreender como o contexto marca tanto a escolha como a aspiração". Desse modo, alinhada às perspectivas que rejeitam enfoques supostamente neutros sobre a justiça ou o bem-estar (Biroli, 2012, 2013), Nussbaum propõe a adoção do enfoque das capacidades, com vistas ao tratamento da "deformação das preferências" e formação das "preferências adaptativas". Para ela, "hábitos, medo, baixas expectativas e condições prévias injustas deformam as escolhas das pessoas e o que esperam de suas próprias vidas" (apud Biroli, 2012, p. 31). Nesse sentido, como assevera Flávia Biroli (2012, p. 17), "as hierarquias de gênero restringem o horizonte do possível para as mulheres", processo atuante na reprodução das desigualdades de gênero e que também se traduz na formulação das políticas sociais.

Há, portanto, uma reiterada tensão para essas mulheres entre a individualização e a maternagem, a rua e a casa, o trabalho extradomiciliar e o papel "do lar". 


\section{Considerações finais}

Para as mulheres que participaram de nossa pesquisa, mulheres pobres, majoritariamente negras, com baixa escolaridade, com menor taxa de participação no trabalho remunerado, em comparação com a média nacional feminina, com altas taxas de grupos domésticos monoparentais e com baixa cobertura de serviços públicos, com destaque para as creches, a conciliação entre trabalho remunerado e cuidado intensifica a sobrecarga decorrente das responsabilidades sociais que recaem sobre elas. Ademais, essa sobrecarga, produto das desigualdades de gênero e raciais, além das de classe, é também suscetível às vicissitudes regionais, de modo que, no geral, as condições das mulheres de Fortaleza apresentam maior vulnerabilidade em comparação com as de Curitiba. Por isso, estamos de acordo com a tese de que aspectos relativos à modernização e ao desenvolvimento humano podem contribuir para a redução das desigualdades de gênero, ainda que essa não seja uma relação necessária, mas sim possível.

Os pontos aqui tratados não se referem diretamente ao desempenho do Programa Bolsa Família, uma vez que o enfrentamento dos problemas subjacentes às desigualdades de gênero não pode ocorrer exclusivamente por meio da transferência de renda. Contudo, ainda assim, evidenciar as tensões constitutivas das experiências dessas mulheres que vivem em situação de pobreza, e estão inseridas nas políticas sociais, contribui para aperfeiçoamentos na formulação dessas políticas. Fundamentalmente, concordando com Nussbaum (2002), torna-se necessário superar o enfoque do bem-estar pelo fato de que tal perspectiva pressupõe a dedicação, e a responsabilização, das mulheres ao trabalho não pago de cuidado do outro. Superar esse enfoque demanda o abandono da lógica de considerar as mulheres "como fim dos outros" e não como "um fim em si mesmas". Entretanto, o cuidado é fundamental, e mesmo indispensável, para a reprodução social. Portanto, torna-se necessário propiciar condições reais que contribuam para a conciliação entre trabalho remunerado e cuidado, ambos considerados como atividades de mulheres e de homens.

A generificação da atividade de cuidado é construída a partir da associação das mulheres a qualquer demanda de cuidado. Daí resulta o fato de que, mesmo que as mulheres não desempenhem diretamente as atividades de cuidado, a responsabilidade principal de tais cuidados recai, em geral, sobre elas. Trata-se, entretanto, do fenômeno social de responsabilização 
das mulheres por essas atividades, atravessado pela estratificação de classe, dado que, para as mulheres pobres, as alternativas do mercado não estão disponíveis.

O enfrentamento das dificuldades aqui apontadas remete ao indispensável debate e revisão dos pilares das políticas sociais, com o necessário afastamento em relação ao modelo, irreal, do provedor universal. Do mesmo modo, a produção de melhores condições de conciliação entre trabalho remunerado e família também envolve a necessidade de reformulações das políticas de emprego, tomando-se em consideração o histórico cenário brasileiro em que as mulheres se inserem em precárias condições de trabalho remunerado. A almejada justiça de gênero requer modelos de intervenção com políticas que, para as mulheres, promovam uma conciliação mais equitativa entre trabalho remunerado e cuidados com a família e, para os homens, proporcionem uma maior responsabilização da paternidade quanto aos trabalhos de cuidado. Ademais, esse conjunto de desafios evidencia a importância de que as teorias feministas se dediquem à teorização do chamado Welfare State, tarefa para a qual relevantes contribuições estão em curso.

\section{Bibliografia}

AGUIAR, Neuma (2001). Múltiplas temporalidades de referência: trabalho doméstico e trabalho remunerado. Análise dos usos do tempo em Belo Horizonte, Minas Gerais: um projeto piloto para zonas metropolitanas brasileiras. Belo Horizonte: FAFICH-UFMG [mimeo].

(2011). "Mudanças no uso do tempo na sociedade brasileira". Política \& Trabalho, n. 34, p. 73-106.

AGUIRRE, Rosario (2005). "Los cuidados familiares como problema público y objeto de políticas", em ARRAIGADA, I. (ed.). Políticas hacia las famílias, protección e inclusión sociales. Santiago, Chile: Cepal-UNFPA (Fundo de População das Nações Unidas) (Série de Seminários y Conferéncias, n. 46).

ARAÚJO, Clara \& SCALON, Celi (2005). "Percepções e atitudes de mulheres sobre a conciliação entre família e trabalho pago no Brasil”, em ARAÚJO, C. \& SCALON, C. (orgs.). Gênero, família e trabalho no Brasil. Rio de Janeiro: Editora FGV.

(2006). "Gênero e a distância entre a intenção e o gesto". Revista Brasileira de Ciências Sociais, v. 21, n. 62, p. 45-68. 
BARDIN, Laurence (2009). Análise de conteúdo. Lisboa: Edições 70.

BECK, Ulrich (2010). Sociedade de risco: rumo a uma outra modernidade. São Paulo: Editora 34.

BIROLI, Flávia (2012). “Agentes imperfeitas: contribuições do feminismo para a análise da relação entre autonomia, preferências e democracia”. Revista Brasileira de Ciência Política, n. 9, p. 7-39.

(2013). Autonomia e desigualdades de gênero: contribuições do feminismo para a crítica democrática. Vinhedo (SP): Horizonte.

BRITO, Alessandra Scalioni (2011). Efeitos esperados pela teoria econômica de políticas de transferência de renda sobre o mercado de trabalho. Rio de Janeiro: UFF (Universidade Federal Fluminense), CEDE - Centro de Estudos sobre Desigualdade e Desenvolvimento. (Texto para discussão, n. 43).

BRUSCHINI, Cristina (1990). Mulher, casa e família: cotidiano nas camadas médias paulistanas. São Paulo: Fundação Carlos Chagas, Vértice.

CAMPOS, Maria Malta et al. (2010). Educação Infantil no Brasil - avaliação qualitativa e quantitativa. Relatório Final. São Paulo: Fundação Carlos Chagas.

CAMPOS, Marta Silva \& TEIXEIRA, Solange Maria (2010). "Gênero, família e proteção social: as desigualdades fomentadas pela política social". Katálysis, v. 13, n. 1, p. 20-28.

CARLOTO, Cássia Maria \& MARIANO, Silvana A. (2008). "A família e o foco nas mulheres na política de assistência social". Sociedade em Debate, n. 14, p. 153-68.

(2009a). "Gênero e combate à pobreza: Programa Bolsa Família". Estudos Feministas, v. 17, n. 3, p. 901-08.

(2009b). "Cidadania na perspectiva das mulheres pobres e papéis de gênero no acesso a políticas assistenciais”. Revista Brasileira de Ciência Política, n. 2, p. 119-57.

(2012). "Empoderamento, trabalho e cuidados: mulheres no Programa Bolsa Família”. Textos e Contextos, Porto Alegre, n. 11, p. 258-72. CASTEL, Robert (1998). As metamorfoses da questão social: uma crônica do salário. Petrópolis (RJ): Vozes.

CRENSHAW, Kimberlé (2002). "Documento para o encontro de especialistas em aspectos da discriminação racial relativos ao gênero". Estudos Feministas, v. 10, n. 1, p.171-88. 
ESPING-ANDERSEN, Gosta (1991). "As três economias do Welfare State". Lua Nova, n. 24, p. 85-115.

(1995). "O futuro do Welfare State na nova ordem mundial". Lua Nova, n. 35, p. 73-112.

FONSECA, Ana Maria Medeiros da (2001). Família e política de renda mínima. São Paulo: Cortez.

FOUGEYROLLAS-SCHWEBEL, Dominique (2009). "Trabalho doméstico”, em HIRATA, H. et al. (orgs.). Dicionário crítico do feminismo. São Paulo: Editora Unesp.

FRASER, Nancy (1999). "A luta pelas necessidades: esboço de uma teoria crítica socialista-feminista da cultura política do capitalismo tardio". Debate Feminista, n. especial, p. 105-41.

GONZÁLEZ DE LA ROCHA, Mercedes (2004). "Familias y política social en México: el caso de oportunidades”. Paper presentado en Reunión de Expertos "Políticas Hacia las Familias, Protección e Inclusión Sociales", Cepal, días 28 e 29 juño de 2005, Santiago de Chile. Disponível em: $<$ http://www.eclac.org/dds/noticias/paginas/2/21682/Mercedes_GdelaRocha.pdf $>$. Acessado em 14. fev. 2006.

GUIMARÃES, Nadya A.; HIRATA, Helena \& SUGITA, Kurumi (2012). "Cuidado e cuidadoras: o trabalho do 'care' no Brasil, França e Japão", em HIRATA, H. \& Guimarães, N.A. (orgs.). Cuidado e cuidadoras. As várias faces do trabalho do care. São Paulo: Atlas.

HABERMAS, Jurgen (1987). "A nova intransparência: a crise do Estado do bem-estar e o esgotamento das energias utópicas". Novos Estudos Cebrap, n. 18, p. 103-14.

INGLEHART, Ronald \& NORRIS, Pippa (2003). Rising tide: gender equality \& cultural changes around the world. New York: Cambridge University Press. IPEA - Instituto de Pesquisa Econômica Aplicada (2011). Retrato das desigualdades de gênero e raça. 4. ed. Brasília: Ipea, SPM (Secretaria de Políticas para Mulheres), ONU Mulheres, SEPPIR (Secretaria de Políticas para a Igualdade Racial).

IPECE - Instituto de Pesquisa e Estratégia Econômica do Ceará (2012). Informe 42: Perfil municipal de Fortaleza. Tema VII: Distribuição espacial da renda pessoal.

IPPUC - Instituto de Pesquisa e Planejamento Urbano de Curitiba (2012). Rendimento. Comparação entre capitais. Análise por bairro. 
IVO, Anete Brito Leal (2004). "A reconversão do social: dilemas da redistribuição no tratamento focalizado". São Paulo Perspectiva, v. 18, n. 2, p. 57-67.

JELIN, Elizabeth (1995). "Familia y género: notas para el debate". Estudos Feministas, v. 2, n. 3, p. 395-413.

(2005). "Las familias latinoamericanas en el marco de las transformaciones globales. Hacia una nueva agenda de políticas públicas", em ARRIAGADA, I. (ed.). Políticas hacia las familias, protección e inclusión sociales. [S.1.]: Naciones Unidas, Cepal.

KERGOAT, Danièle (2009). "Divisão sexual do trabalho", em HIRATA, H. (org.). Dicionário crítico do feminismo. São Paulo: Editora Unesp.

LAVINAS, Lena (2004). "Universalizando direitos". Observatório da Cidadania, n. 8: Relatório 2004: Medos e privações obstáculos à segurança humana, p. 67-74. Disponível em: <http://www.socialwatch.org/sites/ default/files/pdf/en/panorbrasileiroe2004_bra.pdf $>$. Acessado em 18 out. 2015.

(2006). “Transferências de renda: o 'quase tudo' do sistema de proteção social brasileiro", em SICSÚ, J. (org.) Arrecadação (de onde vem) e gastos públicos (para onde vão?). São Paulo: Boitempo.

MDS - Ministério do Desenvolvimento Social e de Combate à Fome (2007). Primeiros resultados da análise da linha de base da pesquisa de avaliação de impacto do Programa Bolsa Família. Brasília: MDS; Cedeplar-UFMG.

MELO, Hildete Pereira de (2005). Gênero e pobreza no Brasil. Brasília: Cepal, SPM (Secretaria de Política para as Mulheres da Presidência da República).

MOLYNEUX, Maxine (2007). "Change and continuity in social protection in Latin America - mothers at the service of the State?". Paper Gender and development programme, n. 1. Geneva: UNRISD (United Nations Research Institute for Social Development).

MOORE, Henrietta L. (1996). Antropología y feminismo. 2. ed. Madrid: Ediciones Cátedra, Universitat de Valencia-Instituto de la Mujer.

NUSSBAUM, Martha (2002). Las mujeres y el desarrollo humano: el enfoque de las capacidades. Barcelona: Herder Editorial.

(2003). "Capabilities as fundamental entitlements: Sen and social justice”. Feminist Economics, v. 9, n. 2-3, p. 33-59. 
(2008). Woman and human development: the capabilities approach. Cambridge: Cambridge University Press.

OLIVEIRA, Francisco de (1988). "O surgimento do antivalor: capital, força de trabalho e fundo público”. Novos Estudos Cebrap, n. 22, p. 8-28.

(2006). "O vício da virtude: autoconstrução e acumulação capitalista no Brasil”. Novos Estudos Cebrap, n. 74, p. 67-85.

PATEMAN, Carole (2000). "El Estado de bienestar patriarcal". Contextos, v. 2, n. $5,[\mathrm{~s} / \mathrm{p}]$.

PEREIRA-PEREIRA, Potyara Amazoneida (2004). "Mudanças estruturais, política social e papel da família: crítica ao pluralismo de bem-estar", em SALES, M. A.; MATOS, M. C. \& LEAL, M. C. (orgs.). Política social, família e juventude: uma questão de direitos. São Paulo: Cortez.

PINHEIRO, Luana et al. (2008). Retrato das desigualdades de gênero e raça. 3. ed. Brasília: Ipea (Instituto de Pesquisa Econômica Aplicada), SPM (Secretaria de Política para as Mulheres da Presidência da República), Unifem (Fundo de Desenvolvimento das Nações Unidas para a Mulher). RAWLS, John (2002). Uma teoria da justiça. 2. ed. São Paulo: Martins Fontes. SARTI, Cynthia Andersen (2005). A família como espelho: um estudo sobre a moral dos pobres. 3. ed. São Paulo: Cortez.

TAVARES, Priscilla Albuquerque (2010). "Efeito do Programa Bolsa Família sobre a oferta de trabalho das mães”. Economia e Sociedade, v. 19, n. 3, p. 613-35.

TEIXEIRA, Clarissa Godim (2011). "Efeitos da transferência de renda na oferta de trabalho". Mercado de trabalho, conjuntura e análise, ano 16, p. 37-44. Brasília: Ipea.

\section{Resumo}

Este artigo interroga as condições que mulheres titulares do Programa Bolsa Família (PBF) enfrentam para a conciliação entre trabalho remunerado e cuidados familiares, os obstáculos para essa conciliação e os possíveis impactos positivos e negativos para a situação delas, com vistas à redução das desigualdades de gênero. Com base em survey realizado em Curitiba (PR) e Fortaleza (CE), aponta as dificuldades para o compartilhamento de tarefas de cuidados domésticos com outros membros familiares e o aumento das responsabilidades em decorrência das condicionalidades do PBF. Como desdobramento dessas dificuldades, destaca as tensões vivenciadas por essas mulheres e reitera a crítica ao enfoque do bem-estar na orientação das políticas públicas. 
Palavras-chave: cuidado, trabalho remunerado, gênero, pobreza, transferência condicionada de renda.

\section{Abstract}

This paper discusses conditions faced by women holders of grants from Program Bolsa Família (PBF) in reconciling paid work and family care, the obstacles to this reconciliation, and the possible positive and negative impacts on the situation of women, with a view to reducing gender inequalities. Based on a survey held in two Brazilian cities, Curitiba (Paraná) and Fortaleza (Ceará), we point out the difficulties in sharing household care tasks with other family members and increasing responsibility as a result of PBF conditions. As an outcome of those difficulties, we highlight the tensions experienced by those women and reiterate the criticism to the welfare approach to public policy.

Keywords: care; paid work; gender; poverty; conditional income transfer.

Recebido em 29 de maio de 2015.

Aprovado em 29 de setembro de 2015. 